\title{
SPERMICIDAL ACTIVITY OF SURFACE-ACTIVE AGENTS
}

\author{
GLARE HARVEY AND R. E. STUCKEY \\ Department of Zoology, Hatherly Biological Laboratories, \\ University of Exeter and The British Drug Houses Ltd.
}

(Received 22nd February, revised 18th August 1961)

\begin{abstract}
Summary. The spermicidal activities against human spermatozoa of a range of non-ionic, anionic and cationic surface-active agents have been determined with the method of Baker, Ransom \& Tynen (1937).

Although it has been concluded that surface-tension-lowering properties do not directly influence spermicidal power, the surfacetension/concentration curves of a number of the compounds were studied.

Solubilities in water, hexane, and ethyl oleate were also determined in an attempt to find out whether there was any relationship between spermicidal action and solubilities in these solvents.

The results obtained on the compounds studied showed broadly that appreciable oil solubility and good surface-tension-lowering properties were desirable for spermicidal activity in non-ionic and anionic surfaceactive agents. The cationic compounds studied were active in spite of low fat solubility.

The lack of precision of the spermicidal results made definite activity/ solubility or activity/surface-tension relationships difficult to formulate.
\end{abstract}

\section{INTRODUCTION}

As early as 1931, Baker investigated the suggestion that substances that lowered surface tension ought to be good spermicides. He found that both sodium oleate and hexylresorcinol were highly active against guinea-pig spermatozoa, although he concluded that there was no direct relationship between capacity to reduce surface tension and spermicidal power. Nevertheless, surface-active agents have been mentioned in the literature on chemical spermicides on a number of occasions since that date. Climenko (1938) reported the activity of sodium dioctyl sulphosuccinate against guinea-pig spermatozoa. Elias (1949) included several classes of neutral aliphatic hydroxy compounds in a United States patent relating to spermicides; the compounds included a wide range of higher alcohols and their glycol ethers, together with the glycol monoesters of long-chain unsaturated fatty acids. In spite of this, Swayne, Beiler \& Martin (1952) reported a number of Spans and Tweens to be inactive against rat spermatozoa, although three samples of Triton were active at concentrations of 1.0 to $0.1 \mathrm{mg} / \mathrm{ml}$. Sander (1951) claimed that the spermicidal 
action of a vehicle containing an unsaturated fatty acid was increased by including, as a wetting agent, a water-soluble alkyl phenoxy ethanol of the general formula $\mathrm{R} \cdot \mathrm{G}_{6} \mathrm{H}_{4} \cdot\left(\mathrm{OC}_{2} \mathrm{H}_{4}\right)_{\mathrm{x}} \mathrm{OH}$, where $\mathrm{R}$ was an alkyl radical with one to twenty-two carbon atoms, $x$ was in the range one to twelve; tertiary octyl phenyl was preferred as $\mathrm{R}$, the substance being $\left(\mathrm{CH}_{3}\right)_{3} \cdot \mathbf{C} \cdot \mathrm{CH}_{2} \cdot \mathrm{C}$. $\left(\mathrm{CH}_{3}\right)_{2} \mathrm{C}_{6} \mathrm{H}_{4}\left(\mathrm{OC}_{2} \mathrm{H}_{4}\right)_{9.75} \mathrm{OH}$.

Mann (1954) stated that there is evidence to show that detergents act directly on the constituents of the lipid-containing outer layer which protects the surface of the spermatozoon. Nevertheless, both Baker (1931) and Swayne et al. (1952) concluded that the spermicidal action of surface-active agents was a function of their chemical structure rather than of their surface-active properties. To obtain more information on this problem, the spermicidal properties of a number of differing types of surface-active agents were determined.

Tests of spermicidal power have been the subject of much comment in recent years and the many factors that affect 'spermicidal concentration' results are being realized. Both Millman (1952) and Davidson (1953) have commented on variations obtained with existing methods for the determination of spermicidal power; in addition, many of the observations recorded in the literature have been made with animal rather than human spermatozoa. In the present work, the preliminary observations in sorting a number of substances were made with the Baker test. First studies were done on three groupsanionic, cationic, and non-ionic surface-active agents. All three groups possess the property of lowering the surface energy of their solvents, but specialized study has produced many variations in each class.

\section{MATERIALS AND METHODS}

Spermicidal activities were determined by the method of Baker et al. (1937). The experimental non-ionic surface-active agents were obtained through the courtesy of Mr G. D. Moore, F.R.I.C., Glovers (Chemicals) Ltd, Leeds, to whom thanks are due; otherwise commercially pure grades of chemicals were used. Solubilities in $n$-hexane were obtained by preparing a saturated solution at $37^{\circ} \mathrm{C}$, evaporating an aliquot to dryness and weighing the residue. Approximate solubilities in ethyl oleate were determined by weight-difference methods. Surface-tension measurements involved the raising of a glass plate from the surface of a solution by means of a simple commercially available Searle Tensiometer.

\section{RESULTS}

\section{NON-IONIC SURFACE-AGTIVE AGENTS}

The group of surface-active agents of this class is usually restricted to those that are water-soluble. Strong hydrophilic groupings are usually ionogenic as shown by the anionic and cationic surface-active agents described later, but certain groups, in particular ether, oxygen and hydroxyl are hydrophilic but non-ionogenic. Modern synthetic methods have made possible the introduction 
of a controlled number of such groupings into a hydrophobic molecule, thus allowing compatibility with water to be varied at will.

The best known and most readily available non-ionic detergents are made by reacting a hydrophobic hydroxy compound with ethylene or propylene oxides according to the following scheme:

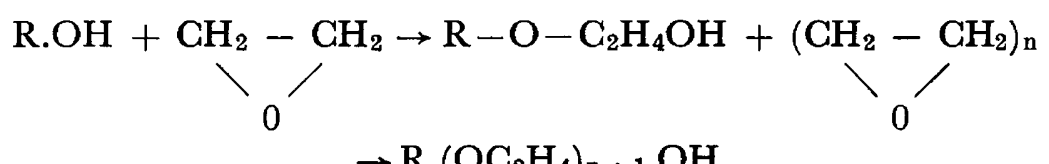

The number of $\left(\mathrm{OC}_{2} \mathrm{H}_{4}\right)$ groups necessary to increase the hydrophilic nature sufficiently to produce water solubility depends on the chain length

TABLE 1

SPERMICIDAL ACTIVITY OF NON-IONIC SURFAGE-ACTIVE AGENTS

\begin{tabular}{|c|c|c|}
\hline Substance & Formula & $\begin{array}{l}\text { Spermicidal } \\
\text { concentration }(\%)\end{array}$ \\
\hline $\begin{array}{l}\text { Hexanol condensate } \\
\text { Butyl phenol condensate } \\
\text { Octanol condensate } \\
\text { Amyl cresol condensate } \\
\text { Dodecyl alcohol condensate } \\
\text { Octyl cresol condensate } \\
\text { Octyl cresol condensate } \\
\text { Octyl cresol condensate } \\
\text { Octyl cresol condensate } \\
\text { Hexadecyl alcohol } \\
\text { condensate } \\
\text { Tridecyl cresol condensate } \\
\text { Castor oil condensate } \\
\text { Diphenylol propane } \\
\text { condensate }\end{array}$ & 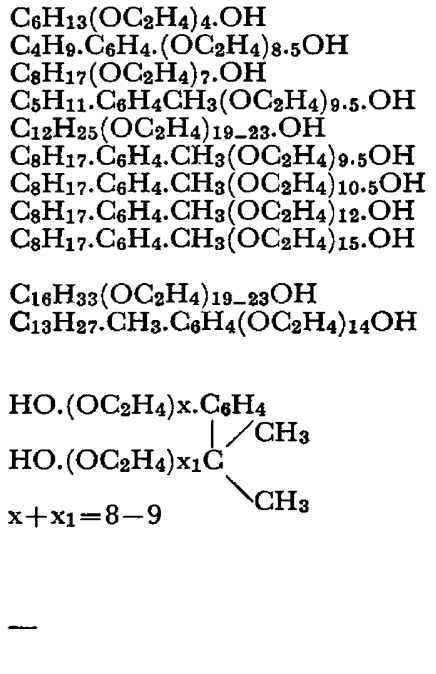 & $\begin{array}{l}0.5 \text { non lethal } \\
0.25 \text { to } 0.125 \\
0.125^{*} \text { to } 0.06 \\
0.125 \text { to } 0.06^{*} \\
0.06 \text { to } 0.03^{*} \\
0.06^{*} \text { to } 0.03 \\
0.06 \text { to } 0.03 \\
0.06^{*} \text { to } 0.03 \\
0.125 \text { to } 0.06^{*} \\
0.06 \text { to } 0.03 \\
0.125 \text { to } 0.06 \text { * } \\
0.5^{*} \text { to } 0.25 \\
0.05 \text { non-lethal }\end{array}$ \\
\hline
\end{tabular}

* Indicates that the lethal concentration is towards this end of the range given. Where no asterisk is shown, the lethal concentration is probably about midway between the two concentrations listed.

and structure of the hydrophobic portion of the molecule. Starting with octadecyl alcohol, for example, the products show complete solubility in water when twelve to fifteen ethylene ether groupings have been introduced; a lower molecular weight alcohol or alkyl phenol would require fewer such groupings.

In the present work, the above principles have been used to vary the properties of the non-ionic surface-active agents and the spermicidal activities of the 
resulting compounds have been determined. The collected results are shown in Table 1. For the purpose of chain-length comparisons, the phenyl group can be considered as approximately equal to 3.5 carbon atoms; both the type of chain and the number of ethylene oxide groupings have been varied.

Surface-active compounds prepared from octyl phenols and octyl cresols are generally available and were first studied; such compounds, however, showed very little water-solubility, until the length of the ethylene oxide chain reached eight units. Elias (1949) had reported spermicidal activity with dispersions of long-chain ethers and hydroxy-compounds of particle size less than $1.5 \mu$ but in the present work dispersions of the insoluble compounds prepared were not easy to make and were not stable, making quantitative work difficult.

In order to study the effect of a small number of ethylene oxide units on spermicidal activity it was necessary (to obtain water solubility) to use a less hydrophobic alcohol - a compound being prepared from $n$-hexanol with four molecules of ethylene oxide. Although this substance was soluble both in water and non-polar solvents (Table 5) and possessed moderate surface tension lowering properties (Table 4), it showed little spermicidal activity, a $0.5 \%$ solution being non-lethal in $30 \mathrm{~min}$ when mixed with an equal volume of semen.

An effective hydrophobic-chain-length increase to tertiary butyl phenol condensate showed increased surface-tension-lowering properties as did an octanol condensate studied; this was accompanied by an increase in spermicidal power. Amyl $m$-cresol condensate showed a further increase in spermicidal power, the maximum properties being exhibited by the dodecyl and octyl cresol condensates these being roughly equivalent in the hydrophobic portion of the molecule. A further increase in chain length to the hexadecyl condensate and the tridecyl-o-cresol condensate produced a lowering in spermicidal power.

Taking the octyl-cresol portion as a constant factor, the number of ethylene oxide units in the compound was then varied, substances with 9.5, 10.5, twelve and fifteen ethylene oxide units being examined. In this series, it was not easy to distinguish the differences between compounds owing to the lack of precision and variability of the test for total spermicidal power being used. A further test was therefore developed for the examination of these compounds (see Harvey \& Stuckey, 1962). Broadly the 9.5- and fifteen-unit compounds were less active than those containing 10.5 and twelve ethylene oxide units.

As a further experiment, a condensation product from castor oil was prepared; this was not spermicidal. The substance, with an $\mathrm{OH}$ group in the middle of the hydrophobic chain had poor fat-solubility and surface-tension-lowering properties. A symmetrical compound-diphenylol propane condensatealso showed little spermicidal activity as did a propylene oxide polymer condensate.

Swayne (1952) reported Spans and Tweens to be inactive against rat spermatozoa. Tween $80-$ an ethylene oxide condensate of sorbitol oleate -in the present work was found to have little activity against human spermatozoa. It also showed relatively poor fat-solubility and surface-tension-lowering properties. Cetomacrogol was also devoid of appreciable spermicidal power. 
The oldest and best known surface-active agents of this group are the soaps, in which the carboxy group serves to solubilize the molecule, and various soaps have long been used as spermicides. Sulphated alcohols R.OSO ${ }_{2} \cdot \mathrm{OH}$ have also been known for some time and the fatty alkyl sulphates are probably the most widely studied of the synthetic anionic detergents; of the many other types of anionic surface-active agents, sodium dioctyl sulphosuccinate has been much studied and has appeared in the literature on spermicides. Table 2 gives the spermicidal activity of three examples of anionic surface-active agents.

Sodium dioctyl sulphosuccinate was outstandingly good as a spermicide. This substance has good surface-tension-lowering properties and is very soluble in fatty solvents as well as in water; Climenko found that it was active in 5 min against guinea-pig spermatozoa at 1 in 1600 . Sodium lauryl sulphate and sodium oleate are less active. Sodium lauryl sulphate is relatively insoluble in fatty and non-polar solvents and possesses relatively poor surface-tension-

TABLE 2

SPERMICIDAL AGTIVITY OF THREE ANIONIG SURFAGE-AGTIVE AGENTS

\begin{tabular}{l|c}
\hline \multicolumn{1}{c|}{ Substance } & $\begin{array}{c}\text { Spermicidal concentration } \\
(\%)\end{array}$ \\
\hline Sodium oleate & 0.5 to 0.1 \\
Sodium lauryl sulphate & 0.25 to 0.125 \\
Sodium dioctyl sulphosuccinate & 0.05 to 0.025 \\
\hline
\end{tabular}

lowering properties; sodium oleate although a good surface-tension-lowering agent is not very soluble in fatty solvents.

CATIONIC SURFACE-ACTIVE AGENTS

The bactericidal activity of these compounds is much greater than that shown by anionic or non-ionic surface-active agents and many compounds in the quaternary ammonium series have been made and studied. The maximum anti-bacterial activity is generally reached with a hexadecyl chain in the cation, and eighteen to twenty-two carbon atoms. Cation active agents are regarded as acting on bacteria by adsorption on the cell wall, followed by disintegration of the cell and final release of vital constituents. It is of interest, therefore, to examine such compounds for spermicidal activity and two readily available substances - benzalkonium chloride and cetyl trimethylammonium bromide were chosen; results are given in Table 3.

Both compounds are active with approximately the same order of activity as the most active anionic and non-ionic surface-active agents examined.

Although it was considered by Baker and by Swayne that surface-tensionlowering properties were not directly connected with spermicidal power, it 
was thought to be of interest to determine the surface tension of solutions of some of the compounds studied. Most of the surface-active agents showed surface-tension/concentration curves that were within the shaded portion of the graph (Text-fig. 1).

Minimum surface tension figures only are recorded in Table 4.

Mann has postulated that the mechanism of action of surface-active agents

TABLE 3

SPERMICIDAL ACTIVITY OF TWO GATIONIC SURFAGE-ACTIVE

AGENTS

\begin{tabular}{l|c}
\hline \multicolumn{1}{c|}{ Substance } & $\begin{array}{c}\text { Spermicidal concentration } \\
(\%)\end{array}$ \\
\hline Benzalkonium chloride & $\begin{array}{l}0.03 \text { to } 0.025 \\
0.1 \text { to } 0.05\end{array}$ \\
\hline
\end{tabular}

may be likened to the haemolytic action of surface-active compounds on erythrocytes, or to their bactericidal effects. Loss of motility occurs and there is an altered permeability of sperm cells resulting finally in leakage of cell contents. Increased surface-tension-lowering properties should, therefore, give increased spermicidal power-and this was very broadly true. Compounds such as diphenylol propane, sodium lauryl sulphate and the castor oil/ethylene

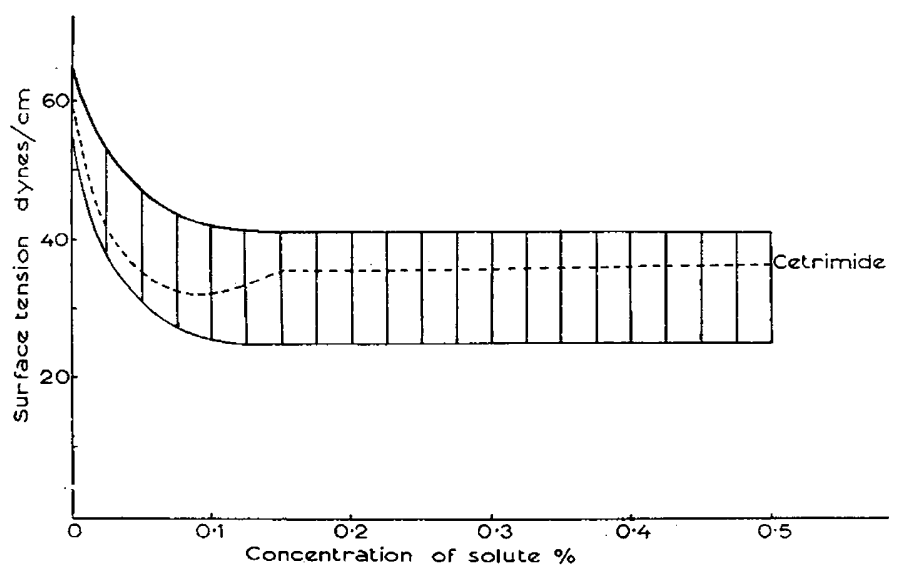

TEXT-FIG. 1. Variation of surface tension with concentration for surface-active agents.

oxide condensate with minimum surface tension greater than 40 dynes $/ \mathrm{cm}$ were relatively inactive. There were, however, slight exceptions in that the hexanol condensate, with minimum surface tension 35 dynes $/ \mathrm{cm}$, was still relatively inactive. The two cation active agents both showed different types of surface-tension/concentration curves (see Text-fig. 1 for cetrimide), and while both compounds were spermicidal at low concentrations, benzalkonium chloride, with greater surface-tension-lowering properties than cetrimide, was also more spermicidal. 
In an attempt to find out whether there was any relationship between spermicidal action and solubilities in water and in organic solvents of varying polarity, the solubilities in water, hexane and ethyl oleate were determined. The results

TABLE 4

MINIMUM SURFACE TENSION OF SOLUTIONS OF GOMPOUNDS STUDIED

\begin{tabular}{l|c}
\hline \multicolumn{1}{c|}{ Substance } & $\begin{array}{c}\text { Minimum surface } \\
\text { tension } \\
\text { (dynes/cm })\end{array}$ \\
\hline Hexanol condensate & 35 \\
Octanol condensate & 30 \\
Amyl cresol condensate & 35 \\
Dodecyl alcohol condensate & 30 \\
Octyl cresol condensate & 33 \\
Tridecyl cresol condensate & 30 \\
Castor oil condensate & 41 \\
Sodium lauryl sulphate & 41 \\
Sodium oleate & 26 \\
Sodium dioctyl sulphosuccinate & 26 \\
Benzalkonium chloride & 26 \\
Cetyltrimethyl ammonium bromide & 33 \\
Diphenylol propane condensate & 48 \\
& \\
\hline
\end{tabular}

are given in Table 5; they show little direct relationship between spermicidal activity and solubility or surface-tension-lowering properties, although the lack of precision of the spermicidal results makes definite relationships difficult to

TABLE 5

SOLUBILITIES OF SPERMIGIDAL AGENTS

\begin{tabular}{|c|c|c|c|}
\hline \multirow{2}{*}{ Substance } & \multicolumn{3}{|c|}{ Solubilities $(\mathrm{g} / 100 \mathrm{~g})$} \\
\hline & Water & $n$-Hexane & Ethyl oleate \\
\hline $\begin{array}{l}\text { Hexanol condensate } \\
\text { Octanol condensate } \\
\text { Amyl cresol condensate } \\
\text { Dodecyl alcohol condensate } \\
\text { Octyl cresol condensate } \\
\text { Tridecyl cresol condensate } \\
\text { Castor oil condensate } \\
\text { Diphenylol propane condensate } \\
\text { Sorbitol oleate condensate } \\
\text { Sodium lauryl sulphate } \\
\text { Sodium dioctyl sulphosuccinate } \\
\text { Getyltrimethyl ammonium bromide }\end{array}$ & $\begin{array}{l}>5.0 \text { readily soluble } \\
>5.0 \text { readily soluble } \\
>5.0 \text { readily soluble } \\
>5.0 \text { readily soluble } \\
>5.0 \text { readily soluble } \\
>5.0 \text { stable colloid. susp. } \\
>5.0 \text { very readily soluble } \\
>5.0 \text { fairly readily soluble } \\
>5.0 \text { slowly soluble } \\
>5.0 \text { readily soluble } \\
\text { about } 2.3 \\
\text { about } 50\end{array}$ & $\begin{array}{l}0.1 \\
0.14 \\
0.12 \\
0.14 \\
0.03 \\
0.05 \\
0.005 \\
0.03 \\
0.005 \\
<0.005 \\
>64 \\
0.02\end{array}$ & $\begin{aligned} & 2 \cdot 87 \\
& 0.9 \\
& 0 \cdot 5 \\
& 4 \cdot 3 \\
& 0.8 \\
& 0.4 \\
& 0 \cdot 23 \\
& 0.3 \\
& 0.2 \\
&<0 \cdot 005 \\
&>20 \\
&<0.01\end{aligned}$ \\
\hline
\end{tabular}

formulate. Nevertheless, for non-ionic and anionic surface-active agents, an appreciable fat solubility and good surface-tension-lowering properties appear to be desirable for spermicidal activity. Cationic surface-active agents (e.g. cetrimide) do not seem to require oil solubility and presumably act by absorption on the cell wall. 


\section{REFERENCES}

BAKER, J. R. (1931) The spermicidal powers of chemical contraceptives. F. Hygiene, 31, 189.

BaKer, J. R., RANSOM, R. M. \& TYNen, J. (1937) The spermicidal powers of chemical contraceptives. VII. Approved tests. F. Hygiene, $37,474$.

Climenko, D. R. (1938) The spermicidal and allied properties of a mixture of sodium dioctyl sulphosuccinate and maleic acid. F. Contraception, 3, 149.

Davidson, H. A. (1953) The contact test. A method of measuring spermicidal action. Lancet, 265, 432.

Eutas, N. M. (1949) United States Patent: 2,467,884.

Harvey, C. \& Stuckey, R. E. (1962) A new method of comparison of spermicidal activities. F. Reprod. Fertil. 3, 132.

Mann, T. (1954) The biochemistry of semen, p. 57. Methuen, London.

Millman, N. (1952) A critical study of methods of measuring spermicidal action. Ann. N.Y. Acad. Sci. $54,806$.

SANDer, F. V. (1951) United States Patent: 2,541,103.

Swayne, V. R., Beiler, J. M. \& Martin, G. J. (1952) Spermicidal effects of certain physiologically active substances. Proc. Soc. exp. Biol. N.Y. 80, 384. 